\title{
Análisis crítico de las actividades prohibidas para las cooperativas de trabajo en Argentina.
}

Critical analysis of prohibited activities for cooperatives of work in Argentina

\section{Análise crítica de atividades proibidas para cooperativas} de trabalho na Argentina

\section{Gustavo Alberto Sosa*}

Recibido: 20 de julio de 2018 Aceptado: 10 de septiembre de 2018

Publicado: 5 de abril de 2019

Cómo citar este artículo:

Sosa, G. A. (2019). Análisis crítico de las actividades prohibidas para las cooperativas de trabajo en Argentina. Cooperativismo \& Desarrollo, 27(1), 1-23. DOI: https://doi.org/10.16925/2382-4220.2019.01.09

Artículo de reflexión. https://doi.org/10.16925/2382-4220.2019.01.09

* Universidad Nacional de Tres de Febrero (Untref). Buenos Aires, Argentina. ORCID: https://orcid.org/0000-0001-7514-7961

Correo electrónico: gsosa@untref.edu.ar 


\section{Resumen}

En 1994, el Poder Ejecutivo nacional de Argentina emitió el Decreto 2015/94, por el cual estableció que el por entonces Instituto Nacional de Acción Cooperativa (INAC), en la actualidad Instituto Nacional de Asociativismo y Economía Social (Inaes), se debería abstener de autorizar a funcionar cooperativas de trabajo que prevean, en el cumplimiento de su objetivo social, contratar servicios cooperativos por terceras personas empleando la fuerza de trabajo de sus asociados. Con el fin de reglamentar dicho Decreto, el INAC emitió la Resolución $N .^{\circ} 1510 / 94$, por la cual declaró comprendidas en dicha situación las solicitudes de autorización para funcionar como cooperativa de trabajo que se vinculen con las siguientes actividades: agencias de colocaciones, limpieza, seguridad, distribuciones de correspondencia y servicios eventuales. De esta manera, se consagró un impedimento al desarrollo de nuevas cooperativas de naturaleza claramente ilegítima, ya que se presuponía, desde el origen, la actividad en fraude a la ley laboral (y, como contracara de la misma moneda, a la norma cooperativa) antes de haberse dado la posibilidad de funcionar a las entidades. El Estado renunciaba así a ejercer su rol de fiscalización, al prohibir lisa y llanamente el desarrollo de determinadas actividades por parte de cooperativas de trabajo. Asimismo, se ponía bajo "manto de sospecha" toda actividad de trabajo cooperativizado que se desarrollara por fuera de un comercio o de una planta fabril. No obstante el tiempo transcurrido y los hechos acontecidos en el país desde entonces, estas prohibiciones mantienen vigencia pese a su manifiesta ilegalidad. Este artículo se propone presentar un desarrollo histórico, desde 1994, de estos hechos, y realizar un análisis crítico de esas normativas, sin dejar de mencionar el daño que estas le han ocasionado al cooperativismo de trabajo nacional. Parte del trabajo será el reflejo de la experiencia del autor como asesor legal del área cooperativa del Inaes, autoridad de registro, promoción y control de las cooperativas y mutuales de todo el país. De igual forma, se recurre a la normativa, la doctrina y la jurisprudencia específica.

Palabras clave: cooperativas de trabajo, fraude laboral, legislación, ley de cooperativas.

\section{Summary}

In 1994, the Argentine National Executive Power issued Decree 2015/94, by which it was established that at that time National Institute of Cooperative Action (inac), currently the National Institute of Associations and Economics Social (Inaes), should abstain from authorizing to work cooperatives that provide, in compliance of its social objective, to contract cooperative services by third persons employing the labor force of its associates In order to regulate said Decree, the inac issued Resolution No. 1510/94, by which it declared Under this situation, applications for authorization to operate as a work cooperative link with the following activities: placement agencies, cleaning, security, correspondence distributions and eventual services. In this way, an impediment to the development of new cooperatives was consecrated of a clearly illegitimate nature, since it was assumed, from the beginning, the activity in fraud to the labor law (and, as counterpart of the same currency, to the cooperative norm) before having the possibility to function the entities. The State thus renounced to exercise its supervisory role, by plainly and simply prohibiting the development of certain activities by worker cooperatives. Also, it was put under "mantle of suspicion" all cooperativized work activity that will develop outside of a trade or a manufacturing plant. However the time elapsed and the events that have taken place in the country since then, these prohibitions remain valid despite its manifest illegality. This article aims to present a historical development, since 1994, of these facts, and carry out a critical analysis of these regulations, not to mention the damage they have caused to the national work cooperativism. Part of the work will be a reflection of the author's experience as legal advisor to the cooperative area of Inaes, registration, promotion and control authority of cooperatives and mutuals throughout the country. Likewise, recourse is made to the regulations, doctrine and specific jurisprudence.

Key words: work cooperatives, labor fraud, legislation, cooperative law. 


\section{Resumo}

Em 1994, o Poder Executivo Nacional da Argentina emitiu o Decreto 2015/94, pelo qual foi estabelecido que naquela época Instituto Nacional de Ação Cooperativa (inac), atualmente o Instituto Nacional de Associações e Economia Social (Inaes), deve abster-se de autorizar a cooperativas de trabalho que prestem, em de seu objetivo social, contratar serviços cooperativos de terceiros empregando a força de trabalho de seus associados A fim de regulamentar o referido Decreto, o decreto emitiu a Resolução n. 1510/94, pela qual Nessa situação, pedidos de autorização para operar como cooperativa de trabalho ligação com as seguintes atividades: agências de colocação, limpeza, segurança, distribuições de correspondência e eventuais serviços. Desta forma, um impedimento para o desenvolvimento de novas cooperativas foi consagrado de natureza claramente ilegítima, já que se assumiu, desde o início, a atividade de fraude ao direito do trabalho (e, como contrapartida da mesma moeda, à norma cooperativa) antes de ter a possibilidade de funcionar as entidades. O Estado renunciou assim a exercer seu papel de supervisão, ao proibir clara e simplesmente o desenvolvimento de certas atividades por cooperativas de trabalhadores. Além disso, foi colocado sob "manto de suspeita" todos atividade de trabalho cooperativista que se desenvolverá fora de um comércio ou de uma fábrica. Não obstante o tempo decorrido e os eventos que ocorreram no país desde então, estas proibições permanecem válidas apesar de sua ilegalidade manifesta. Este artigo tem como objetivo apresentar um desenvolvimento histórico, a partir de 1994, desses fatos, e realizar uma análise crítica destes regulamentos, para não mencionar os danos que eles causaram ao cooperativismo nacional do trabalho. Parte do trabalho será um reflexo da experiência do autor como assessor jurídico do área de cooperação da Inaes, autoridade de registro, promoção e controle de cooperativas e mútuas em todo o país. Da mesma forma, recorre-se aos regulamentos, doutrina e jurisprudência específica.

Palavras-chave: cooperativas de trabalho, fraude trabalhista, legislação, legislação cooperativa.

\section{Introducción}

Desde la Constitución Nacional de la República Argentina, la cual proviene del proceso constitucional del periodo 1853-1860, hasta la actualidad -con la última reforma al texto constitucional de 1994-, su artículo 14 prevé que todos los habitantes de la Nación gozan de los derechos - en conformidad con las leyes que reglamenten su ejercicio- de "trabajar y ejercer toda industria lícita", y de "asociarse con fines útiles", entre otros. Por su parte, el artículo 14 bis -incorporado en la reforma de 1957- establece que el trabajo "en sus diversas formas" debe gozar de la protección de las leyes.

Las primeras cooperativas de trabajo del país se crearon a fines de la década de los veinte del siglo pasado. En dicha época se sancionó la primera Ley de Cooperativas nacional (Ley 11.388 de 1926). A partir de entonces, el cooperativismo de trabajo se desarrolló a los largo de todo el territorio, de modo que se conformaron entidades dedicadas no solo a la elaboración de productos, sino también a la prestación de una gran variedad de servicios. 
De acuerdo con la Ley 20.337 de Cooperativas de 1973, actualmente en vigencia, las cooperativas son "entidades fundadas en el esfuerzo propio y la ayuda mutua para organizar y prestar servicios"; de esta manera, no establece - de forma expresa- ninguna prohibición en cuanto a las actividades que pueden realizar.

En Argentina, en la década de los noventa del siglo Xx, bajo la presidencia del Dr. Carlos Saúl Menem y en un contexto de políticas económicas de corte -en gran medida- neoliberal, el cooperativismo sufrió diversas crisis, bien fuera por acción o bien por omisión del Estado, así como en razón del contexto económico: la caída de la cooperativa de consumo El Hogar Obrero, la disolución de numerosos bancos cooperativos y el hostigamiento al cooperativismo de seguros, entre otras situaciones. El cooperativismo de trabajo no fue ajeno a esa avanzada, de modo que fue el mayor exponente de la situación crítica la emisión, por parte del Poder Ejecutivo nacional, del Decreto 2015/94, el cual, bajo la excusa de defender los principios y la naturaleza propia de las cooperativas, terminó por adoptar una regulación fuertemente discriminatoria y prejuiciosa.

La paradoja es que esa decisión -la cual dejaba claramente en evidencia la mirada que sobre la figura cooperativa se extendía entonces desde los más altos niveles de la administración pública - se tomaba en una coyuntura en la que se privatizaban los principales servicios públicos nacionales, cuyos concesionarios -en numerosas ocasiones- apoyaron la conformación de empresas tercerizadoras de trabajo -incluso cooperativas-, tal como ocurrió, por ejemplo, en el caso de los ferrocarriles, del correo o de la electricidad, entre otros.

Esta investigación se propone analizar el Decreto 2015/94 y su reglamentación, así como los efectos dañinos que se causaron a la imagen del cooperativismo. De igual forma, los aspectos que lo tornan constitucional y legalmente repudiable, para luego establecer si es pertinente o no la subsistencia de esa normativa a casi 25 años de su emisión.

\section{El cooperativismo de trabajo en Argentina}

Existe un consenso general en ubicar las primeras cooperativas de trabajo del país a finales de la década de los veinte del siglo pasado. Señala Vuotto (2017) que, según los registros de cooperativas, entre 1928 y 1950 las cooperativas de trabajo representaban el 3,9\% del total de entidades (p. 17); luego, se incrementó su número de forma lenta pero continua, de manera que abarcaron un mayor ámbito de actividades tanto con respecto a la producción como a los servicios. 
Las sucesivas crisis económicas hicieron mella no solo en los índices de pobreza, sino también en los de desocupación, de manera que fue la cooperativa de trabajo una herramienta cada vez más empleada por los trabajadores. A los rubros propios del sector industrial y de trabajo agrario se sumaron empresas asociativas que brindaron servicios como, por ejemplo, los de limpieza y mantenimiento, seguridad y vigilancia, educación, gastronomía, construcción y arreglos en el hogar, etc.

Con las privatizaciones de la década de noventa surgieron también cooperativas de trabajo conformadas por personas vinculadas a las empresas del Estado nacional que brindaban servicios públicos -trenes, correos, energía, entre otros-.

La crisis socioeconómica de comienzos del nuevo siglo conllevó el surgimiento de cientos de empresas recuperadas por sus trabajadores, las cuales adoptaron la figura de cooperativa de trabajo a fin de continuar con su explotación. A partir del Gobierno kirchnerista entre otroscomo se verá más adelanteentre otros surgieron miles de cooperativas de trabajo impulsadas por diversos planes y programas ejecutados por el Estado nacional.

Por todo lo anterior, en las últimas décadas el incremento de cooperativas de trabajo ha sido exponencial. Esta tendencia se mantiene en el 2018, aun después de que se hayan discontinuado políticas públicas sociales que alentaban las conformación de las cooperativas con personas en situación de vulnerabilidad social mediante otras estrategias ${ }^{1}$.

Como botón de muestra de la importancia cuantitativa de la presencia del cooperativismo de trabajo en el país, cabe señalar que en el 2015 entre otrosúltimo año de la presidencia de la Dra. Cristina Kirchnerentre otros se aprobaron 1919 nuevas matrículas, lo que supuso el 92 \% del total. Pese a que el número total de matrículas cooperativas descendió en los dos primeros años del Ing. Mauricio Macri, las cooperativas de trabajo son aún mayoría: en el 2016 se aprobaron 486 - un 85,5\% del total anual-, y en el 2017 fueron 501 - un 92,2 \% del total anual, porcentaje similar al del 2015-.

Al mes de agosto de 2018, de acuerdo con la información disponible en el buscador de entidades cooperativas del Instituto Nacional de Asociativismo y Economía Social ${ }^{2}$, se encontraban vigentes un total de 29944 entidades, lo que corresponde a 29767 a cooperativas de primer grado. Del total de estas últimas, el 78,4 \% (23 478) eran cooperativas de trabajo (Sosa, 2018.)

1 En el 2018, por ejemplo, se implementó el Programa Hacemos Futuro.

Véase http://www.hacemosfuturo.gob.ar/

2 Véase http://www.inaes.gob.ar/Entidades/BuscarEntidades 
6 Análisis crítico de las actividades prohibidas para las cooperativas de trabajo en Argentina

\section{El Decreto PEN 2015/94 y su reglamentación}

El 16 de noviembre de 1994 se publicó en el Boletín Oficial de la República Argentina el Decreto 2015/94, suscripto por el presidente Menem. Este Decreto merece un análisis, a partir de sus principales considerandos, en los cuales se dejan en claro no solo las razones que motivaron la emisión de esta norma, sino también la forma en que se percibía en ese momento desde lo más alto del Poder Ejecutivo nacional el cooperativismo de trabajo en particular. Así, señala lo siguiente:

En los últimos años han proliferado cooperativas de trabajo que, en violación del fin de ayuda mutua y esfuerzo propio, principios rectores de su naturaleza, actúan en la práctica como agencias de colocaciones, limpieza, seguridad, distribución de correspondencia o empresas de servicios eventuales.

Se reparaba entonces en la vulneración de la figura cooperativa que esta situación generaba, con el consiguiente beneficio que obtenían las personas que abusaban de ella:

Que por lo tanto, un tipo asociativo basado en valores trascendentes de solidaridad, es así desvirtuado para aprovechar su estructura formal, situación ésta que permite obtener ventajas impositivas, eludiendo además las obligaciones para con la Seguridad Social generándose una evidente competencia desleal respecto de las empresas comerciales que brindan servicios similares.

Adviértase cómo al final del párrafo anterior se hace fuerte hincapié en el hecho de que la "competencia desleal" que se le adjudica a esas cooperativas iba en detrimento de "las empresas comerciales que brindan servicios similares", cuando también lo era respecto de otras cooperativas que cumplían con todas las regulaciones. En este párrafo, como en ningún otro, es claro cómo a quienes había que defender era a las empresas comerciales - por ejemplo, las sociedades anónimas o las de responsabilidad limitada-, y es en sí misma la cooperativa de trabajo la figura legal bajo el "manto de sospecha".

En esa línea, el Poder Ejecutivo nacional consideró necesario "limitar la autorización para funcionar a las cooperativas de trabajo que tengan por fin exclusivo la obtención de un logro comunitario, mediante el servicio personal en provecho o en 
beneficio de sus socios". Por tanto, impidió al por entonces Instituto Nacional de Acción Cooperativa-INAC -actualmente Instituto Nacional de Asociativismo y Economía Social-, la posibilidad de registrar a "aquellas sociedades que suministran mano de obra a terceros".

Con relación al aspecto reglamentario propiamente dicho, el artículo 1 del Decreto 2015/94 estableció:

el Instituto Nacional de Acción Cooperativa, organismo dependiente de la Secretaría del Industria del Ministerio de Economía y Obras y Servicios Públicos de conformidad con las facultades que le otorga el artículo 106 de la Ley 20.337 no autorizará, a partir de la publicación del presente Decreto, el funcionamiento de cooperativas de trabajo que, para el cumplimiento de su objetivo social, prevean la contratación de los servicios cooperativos por terceras personas utilizando la fuerza de trabajo de sus asociados.

Es claro que en el Decreto 2015/94 el Poder Ejecutivo nacional emitió una disposición de naturaleza legislativa que limita el derecho a asociarse con fines útiles (art. 14 de la Constitución Nacional). Además, no lo realizó empleando la figura del decreto de necesidad y urgencia, sino la de un decreto común.

Cabe recordar que el nuevo texto constitucional, aprobado en 1994 por la Asamblea Constituyente, y luego por el Congreso Nacional por medio de la Ley 24.430, entró en vigencia en los primeros días de 1995, escasas semanas después de la publicación del Decreto 2015/94 en el Boletín Oficial. Fue en ese texto constitucional en el que se estableció con claridad el hecho de que el Poder Ejecutivo no puede "en ningún caso bajo pena de nulidad absoluta e insanable, emitir disposiciones de carácter legislativo", con la salvedad de los denominados "decretos de necesidad y urgencia", los cuales requieren el acuerdo general de los ministros del Gabinete nacional (art. 99, inc. 3, Constitución Nacional).

No obstante, es cierto que tampoco bajo el anterior texto constitucional el Poder Ejecutivo nacional podía emitir normas de naturaleza legislativa, mas sí podía expedir "las instrucciones y reglamentos que sean necesarios para la ejecución de las leyes de la Nación, cuidando de no alterar su espíritu con excepciones reglamentarias" (art. 86, inc. 2 de la Constitución Nacional, texto 1853/60). Esta redacción se repite en su totalidad en el actual artículo 99, inc. 2, de la Constitución Nacional, conforme el texto aprobado en 1994. 
Los reglamentos (decretos) del Poder Ejecutivo nacional han sido en numerosas ocasiones objeto de crítica por parte de la doctrina calificada, dada la tendencia de este Poder del Estado a incurrir en excesos en su facultad reglamentaria. Agustín Gordillo ha sido uno de sus críticos, quien no ha dudado en señalar que,

De alguna manera el reglamento es la fuente de más ilegalidad y arbitrariedad en el campo de la administración. En ninguna otra parte del derecho administrativo se consagra tanto la arbitrariedad, el capricho, la autocontradicción, la improvisación e imprevisión, las contramarchas, la desviación de poder. No es en los actos individuales donde la administración despliega toda su arbitrariedad: Es en la redacción de largos reglamentos, seudo normas generales que luego alega limitarse a cumplir, cuando ella los ha preparado y emitido (2011, p. 22)

Asimismo, el Decreto 2015/94 dispuso que tanto la autoridad impositiva nacional como la que ejerce el rol de policía de trabajo, en el ámbito de sus competencias, debían proceder "a verificar la existencia de fraude laboral y/o evasión de los recursos de la Seguridad Social, en aquellas cooperativas que se encuentren en actividad", de conformidad con la información que debía suministrarles el antigua INAC. En dicho orden, instruía a aquellas dependencias a que, una vez labradas las actuaciones administrativas de las que surgiera la "existencia de fraude laboral o evasión a los recursos de la Seguridad Social", remitiera copia certificada de estas y su respectivo informe a la autoridad de aplicación en materia cooperativa, a fin de que esta tome las medidas de acuerdo con las facultades y atribuciones que le otorga la Ley 20.337 de Cooperativas.

Otra característica que muestra la parcialidad de esta reglamentación es que siempre hace referencia al fraude laboral y nunca al fraude cooperativo, de modo que - a la hora de constatarse el empleo de la cooperativa de trabajo como una "fachada" de empresa asociativa, pero con el fin real de vulnerar derechos de trabajadores a favor de un grupo de personas inescrupulosas) cada una sería una cara de la moneda: la existencia una "seudo-cooperativa de trabajo" o una "cooperativa de trabajo trucha" - como se suele denominar en Argentina a estas situaciones de anomalía de la figura cooperativa - vulnera no solo el régimen de contrato de trabajo bajo una relación de dependencia y el régimen de seguridad social, sino también se lleva a cabo un fraude a la legislación cooperativa. Sin embargo, esto último siempre se deja de lado a la hora de evaluar el marco legal integral como un sistema. 
La publicación del "2015" - como también se ha vuelto usual referirse a esta en los ambientes cooperativos- Ilevó a la autoridad de aplicación a emitir una resolución en consecuencia, la número 1510/94 (B. 0. 16/12/1994). Si bien esta procuró morigerar la cruda y amplia mirada de sospecha que el Decreto expandió sobre las cooperativas de trabajo, continuó la línea discriminatoria allí expresada.

En efecto, en uno de sus considerandos se lee:

Entre los tipos de actividad a los que se refiere el considerando tercero del Decreto 2015/94 se menciona a las Cooperativas de Seguridad y Vigilancia, respecto de las que se aprecia, independientemente de lo expresado en el decreto, que sus características resultan inadecuadas a la práctica de la democracia cooperativa, habida cuenta de la situación de preeminencia que detentan quienes están en condiciones de acceder a las autorizaciones extra cooperativas necesarias.

Como puede advertirse, las características que hacen a este tipo de cooperativas merecedoras del rechazo normativo no son claras, de manera que queda en el aire un fuerte "tufillo" a prejuicio de existencia de fraude por el solo hecho de realizar determinadas actividades - previstas en sus propios objetos sociales-.

En el relato de los considerandos de la Resolución 1510 se menciona a continuación a las cooperativas de trabajo con actividad en el ámbito rural, en las que, efectivamente - cabe reconocer- se constataron casos de fraude a la legislación laboral y cooperativa, con entidades que eran meras colocadoras de personal ${ }^{3}$ y carecían de los mínimos estándares de funcionamiento cooperativo:

Que el mencionado Decreto, en sus textos más significativos en cuanto a las cooperativas de trabajo que deben entenderse comprendidas en la prohibición de matrícula, hace referencia a aquellas que "suministran mano de obra a terceros...." y a la "contratación de los servicios cooperativos por terceras personas utilizando la fuerza de trabajo de sus asociados", lo que resulta descriptivo de los casos en que se proporcione a terceros empresarios la fuerza de trabajo necesaria para la ejecución de las tareas específicas de estos últimos. Tal es el caso de las Cooperativas de cosecha, poda, tala, entre otros.

\footnotetext{
3 Son conocidos los casos de cooperativas de trabajo tales como Agrícola Colonia Barraquero o Eventur.
} 
La morigeración de la mirada que plantea el Decreto 2015 se evidencia cuando en uno de los considerandos de la Resolución 1510/94 se procura dejar a salvo a un grupo de cooperativas de trabajo que brindan determinados servicios:

Otras cooperativas de trabajo, aun cuando tengan por objeto actividades de servicios, es decir, no manufactureras, se encuentren en situación diferente de la descripción que precede, ubicándose, en cambio, dentro de la contenida en el considerando quinto que hace referencia, para mantener la autorización a su respecto, a las Cooperativas de Trabajo que tengan por fin exclusivo la obtención de un logro comunitario, mediante el servicio personal en provecho o en beneficio directo de sus socios. En esa línea se hace mención expresa a las Cooperativas de Trabajo Docente, de Asistencia Hospitalaria, de Transporte de Pasajeros o de Carga, etc., que vayan a operar sus propios establecimientos o equipos.

Dicho esto, el Directorio del Instituto resolvió considerar que en el artículo 1 del Decreto 2015/94 se comprenden "las solicitudes de autorización para funcionar como cooperativa de trabajo que se vinculen con las siguientes actividades: Agencias de Colocaciones; Limpieza; Seguridad; Distribuciones de Correspondencia y Servicios Eventuales".

Es decir, se tomaron en cuenta las actividades expresamente señaladas en uno de los primeros considerandos del Decreto N. ${ }^{\circ}$ 2015/94.

El segundo párrafo del artículo 1 hace extensiva a otros casos la "auto-prohibición", cuando se advierta lo que - de forma simplificada- implicaría la tercerización de trabajadores de cooperativas de trabajo en otras empresas:

Asimismo se considerarán comprendidos aquellos casos en que la descripción del objeto social contenida en los estatutos revele que se trata de la venta de fuerza de trabajo o mano de obra a terceros para dedicarlas a las tareas propias o específicas del objeto social de los establecimiento de estos últimos, de tal manera que dicha fuerza de trabajo o mano de obra constituya un medio esencial en su producción económica.

También quedó en tela de juicio qué pasaría con las cooperativas de trabajo con autorización para funcionar de acuerdo con lo estipulado antes en el Decreto 2015; el artículo 2 de la Resolución 1510/94 reconoció que estas tenían un derecho adquirido que no se podía cercenar, pues señala que respecto a aquellas entidades que estaban 
constituidas "o que se constituyan en el futuro no se admitirán reformas estatutarias que incorporen al objeto social de las cooperativas actividades como las descriptas en el artículo anterior".

Así, entonces, ninguna de las dos normas reseñadas hace mención a casos específicos, ni a datos estadísticos, ni a cantidad de denuncias existentes en ámbitos administrativos o judiciales. Son normas que carecen de una notoria falta de fundamentación, las cuales no solo no pasarían un examen serio de control de constitucionalidad, sino que, además - desde la mirada del derecho administrativo-constituirían actos generales viciados de varias nulidades, como, por ejemplo, la que genera la falta de debida fundamentación del acto -elemento "motivación"-. Sin embargo, queda en el aire la pregunta sobre su vigencia en el $2018 .{ }^{4}$

\section{Críticas al Decreto 2015/94. Consecuencias}

Desde el primer momento, la doctrina cooperativa se mostró crítica con la sanción del Decreto 2015/94 y su reglamentación.

A título de ejemplo cabe recordar cómo, en numerosas ocasiones, Aarón Gleizer criticó los efectos de esta normativa y su carácter pernicioso. Así, con relación a dos de los tantos proyectos de ley específicos para cooperativas de trabajo que se presentaron en el Congreso de la Nación - sin éxito- señaló:

Reviste gran importancia que estas cooperativas, cuyo mayor potencial de desarrollo parecería verificarse en las actividades mano de obra intensivas cualquiera fuera la calificación profesional requerida, cuenten con un marco regulatorio adecuado, porque las normas inapropiadas dictadas en su ausencia (Decreto PEN N.․ 2015/ 94 y Resolución INAC N. ${ }^{\circ}$ 1510/94) afectaron y produjeron el cierre de muchas entidades. (Gleyzer, 1997a).

En otra ocasión afirmó:

El tema de la autenticidad cooperativa constituye una preocupación permanente de los cooperadores, ya expuesta por Juan Bautista Justo.

4 Por la Resolución Inaes 1810/07 del propio Inaes se consideró a la Resolución N. 1510/94 entre las disposiciones vigentes de dicha autoridad de aplicación para las cooperativas. 
Pero perseguir este objetivo sin incurrir en las desviaciones que en forma impropia y contraproducente alegaron corregir el Decreto PEN N. ${ }^{\circ}$ 2015/94 y la Resolución INAC N. ${ }^{\circ} 1510 / 9432$ no justifica la existencia de un espíritu de sospecha preventiva o generalizada por la mera figura jurídica, que aparecía en algunos proyectos antecedentes, felizmente suprimidos en la versión consensuada (Gleyzer, 1997b).

Schujman también ha señalado las notables deficiencias de estas normas:

El decreto 2015/94, dictado en el apogeo neoliberal, invocando el fraude laboral, prohibía la prestación de "los servicios de las cooperativas a terceras personas utilizando la fuerza de trabajo de sus asociados". Es decir que comprendía a todas las cooperativas de trabajo. Es muy distinto "vender mano de obra o trabajo de los asociados a terceros", que "vender los servicios de la cooperativa utilizando la fuerza de trabajo de sus asociados". Las contradicciones normativas no explicitadas, incrementaron los desencuentros doctrinarios y jurisprudenciales (Schujman, 2016, p. 43)

Es necesario aclarar que la doctrina laboralista, por lo general, ha apoyado normativas como las aquí revisadas, basada en una mirada crítica compartida con respecto a las cooperativas de trabajo, las cuales pondrían en peligro las conquistas conseguidas por los trabajadores bajo relación de dependencia desde hace muchos años.

Estas posturas críticas - desde el sector doctrinario y judicial laboral-hacia las cooperativas de trabajo fueron reiteradas cuando la Corte Suprema de Justicia de la Nación, en el 2009, se manifestó con respecto a la relación de naturaleza asociativa que existe entre los trabajadores cooperativistas y sus entidades. ${ }^{5}$

No obstante, destacados referentes del derecho laboral argentino entendieron equívoca la perspectiva del Decreto 2015/94. Entre ellos, Cornaglia manifestó:

Los fundamentos del Decreto 2.015/94 demuestran que el poder administrador en esta materia, operando por vía reglamentaria, intentó operar contra el fraude que constatara como autoridad de aplicación. Pero si bien la constatación responde a la realidad, lamentablemente se cometieron gruesos errores jurídicos, producto de una prejuiciosa actitud contra este tipo de asociaciones (Cornaglia, 2003, p. 516).

5 Para conocer más sobre este fallo y la reacción del ámbito laboral, véase Sosa (2012). 
Ahora bien, ¿cuáles han sido las consecuencias directas de estas normas?

Desde su entrada en vigencia, la autoridad de aplicación ha rechazado todo trámite constitutivo de una cooperativa de trabajo en cuyo objeto social se haga expresa mención a alguna de las actividades referidas en el artículo $1^{\circ}$ de la Resolución 1510/94 -en el siguiente apartado se analizan las excepciones a lo aquí señalado-.

Se generó así una fuerte inseguridad jurídica en lo que se refiere a aquellas entidades -incluso el propio Estado- que contratan los servicios de estas cooperativas -las que mantuvieron vigente su matrícula-. Incluso la doctrina negativa sobre la que se sostienen estas regulaciones perjudicó a cooperativas de trabajo en procedimientos de licitaciones públicas, de modo que muchas de ellas quedaron -en diversas ocasiones y a causa de estas razones- por fuera de importantes compulsas -esto pese a que sobre la entidad en cuestión no existía una sola sanción por parte de la autoridad de aplicación-

Asimismo, se profundizó e incluso se justificó la percepción, por lo general negativa, de las cooperativistas de trabajo que existía en determinados ámbitos, como, por ejemplo, en el de los tribunales laborales, en el de los sindicatos o en el de los abogados laboralistas, así como en los medios de comunicación.

El sector cooperativo, en general, y el de las cooperativas de trabajo en particular, pidió en numerosas ocasiones que esta normativa restrictiva se dejara sin efecto, mas no obtuvo un resultado favorable. Por otra parte, no se contaba con casos que justificaran la emisión de una jurisprudencia contraria a estas normas, en gran parte porque aquellas personas que querían conformar una cooperativa que prestara algunos de esos servicios "prohibidos" o bien desistían del trámite, eliminaban de su objeto social esa actividad que se encontraba prevista en el artículo $1^{\circ}$ de la Resolución 1510/94, disfrazaban esas actividades bajo una redacción distinta, o bien -en el peor de los casos- prestaban esos servicios fuera de lo previsto en sus estatutos sociales.

Esta situación se mantiene incluso luego de que destacados organismos internacionales como la Organización de Naciones Unidas (ONU) y la Organización Internacional del Trabajo (OIT) han emitido trascendentales pronunciamientos de respaldo a las empresas cooperativas. Por ejemplo, la Recomendación sobre la Promoción de las Cooperativas 193 del año 2002 de la OIT, alienta a los Gobiernos a "prever la adopción de medidas de supervisión de las cooperativas acordes con su naturaleza y funciones, que respeten su autonomía y sean conformes con la legislación y las prácticas nacionales y no menos favorables que las medidas aplicables a otras formas de empresa y de organización social"6.

6 El texto completo se encuentra disponible en web de la oit: https://www.ilo.org/ 


\section{¿Se encuentra vigente el Decreto 2015/94? Pautas para el análisis}

Si bien tanto el Decreto 2015/94 como la Resolución INAC 1510/94 mantienen vigencia en las páginas oficiales y privadas de consulta normativa, existen sobrados motivos para pensar que el transcurso de los hechos que a continuación se explicitarán, así como la sanción de leyes por parte del Congreso, los han derogado de hecho. Esto, por supuesto, no implica que se hayan derogado todas las prohibiciones que existen para las cooperativas de trabajo.

A continuación, señalaremos cuatro acontecimientos que se han dado con el transcurrir del tiempo, los cuales nos permiten afirmar-adelantamos nuestra respuesta- que el Decreto 2015/94, pese a no haber sido derogado expresamente, ha perdido fuerza legal, de manera que sigue este camino la resolución de la autoridad de aplicación en materia cooperativa que lo reglamenta.

Incluso, ante el caso en que se considerara un exceso o una osadía señalar que el Decreto 2015/94 se encuentra derogado de hecho, existen razones más que suficientes para afirmar que la autoridad de aplicación en materia cooperativa -el Inaes"debe" modificar la Resolución 1510/94, adecuándola a la actual realidad normativa.

\section{La cooperativización por mecanismos "alternativos"}

Partamos del relato de un caso hipotético, pero basado en hechos reales. Somos un grupo de personas que sabemos cómo realizar la limpieza integral de oficinas, de galpones, de edificios y espacios cerrados y abiertos. Conocemos no solo las técnicas, sino cuáles son los productos a emplear cuando se higienizan determinados espacios - los consultorios de una clínica médica-. Decidimos organizar una empresa conjunta con el propósito de de prestar este servicio y, dado que queremos generar una herramienta para trabajar - derecho reconocido por nuestra Constitución Nacional-, la cual nos permita ejercer democráticamente la toma de decisiones, de forma autogestiva, sin patrones ni empleados, decidimos conformar una cooperativa de trabajo. Cuando consultamos a un especialista en cooperativas, le informamos que nuestro servicio esencial será la limpieza. El experto pone cara de horror y nos explica que esa actividad "está prohibida" por el Estado y nunca nos van a otorgar la autorización para funcionar, de modo que lo mejor sería conformar otra persona jurídica, como, por ejemplo, una sociedad de responsabilidad limitada (s. R. L.), en la que cada uno "vale" en conformidad con el capital que aporta. Nosotros, quienes en un momento determinado de la consulta al profesional sentimos que 
habíamos confesado querer cometer un crimen grave - sin saber que esa acción era así considerada por el Estado- preguntamos si existe alguna forma de conformarnos como cooperativa de trabajo. Es entonces cuando un experto menciona un término clave, la llave que abre la puerta a nuestro soñado trabajo autogestionado: "mantenimiento". Nos dice que en el objeto social no se nos ocurra consignar "limpieza", y que hablemos en cambio de "mantenimiento", ya que esta expresión no está prohibida y, además, denota una actividad más amplia que la de limpieza, a la cual engloba:

Fíjense — nos señala-, conforme el diccionario de la Real Academia Española, una de las acepciones de la expresión "mantenimiento" es aquella que hace referencia al "conjunto de operaciones y cuidados necesarios para que instalaciones, edificios, industrias, etc., puedan seguir funcionando adecuadamente." Y ustedes, en definitiva, van a hacer eso, mantener en condiciones distintos espacios.

Así es como obtuvimos la matrícula de nuestra cooperativa, "escondiendo" bajo la expresión "mantenimiento" la principal actividad que realizamos, que es la limpieza.

Si bien esta historia no se basa en un caso puntual, toma como fuente un montón de situaciones que se dieron -y se dan- en la realidad. Muchas cooperativas de trabajo que, entre otras actividades, realizan tareas de limpieza, obtuvieron su matrícula después de la expedición del Decreto 2015/94, al eliminar de sus estatutos sociales esa palabra que, en definitiva, es la denominación de una actividad totalmente legal que adelantan innumerables personas de manera independiente -bien sea bajo una relación de dependencia o no- como empresas de capital, a las cuales nunca se les cuestiona el hecho de prestar ese servicio.

Se evidencia entonces un conjunto de entidades que lograron superar el escollo que les oponía el Decreto 2015 y su reglamentación, pero las cuales tuvieron que adaptar la redacción de sus estatutos por una prohibición legal.

Historias semejantes se pueden encontrar con hombres y mujeres que quisieron conformar cooperativas que llevan a cabo actividades de servicios de mensajería en moto en las grandes urbes -consignar la expresión "correo" les supuso grandes dolores de cabeza-, o que se especializaron en el cuidado de personas o de sus patrimonios frente a situaciones de inseguridad -allí la expresión de actividades de "seguridad" es la que obstruye todo avance en el trámite registral-.

Asimismo, cabe señalar que existieron varios casos de creación de cooperativas de provisión de servicios — no de trabajo— para "idóneos" en limpieza y seguridad. 


\section{Programas sociales implementados por el Estado}

Desde comienzos del Gobierno del Dr. Néstor Kirchner (2003), en el marco de la profunda crisis socioeconómica de principios de siglo, se decidió recurrir a la conformación de cooperativas de trabajo como una herramienta de política social. De esta forma, se procuraba poner en marcha una estrategia de generación de nuevos puestos de trabajo y de ingresos para los sectores más castigados por la crisis. Se desarrollaron así numerosos programas y planes sociales -"Manos a la Obra", "Aguas más Trabajo", "Argentina Trabaja", "Ellas Hacen", entre otras- que tuvieron como eje la conformación de nuevas cooperativas de trabajo, de modo que se generaron miles de nuevas entidades.

En el marco de dichas políticas, la Resolución 3026/06 del Inaes -aún vigente- previó un sistema procedimental específico para autorizar el funcionamiento de estas cooperativas de trabajo, así como aprobó modelos de estatutos para ellas en los cuales se podían consignar distintas actividades sin limitación alguna. De hecho, en uno de los considerandos de la Resolución, al referirse a las razones por las cuales se derogaba una resolución anterior (la 2038/03), se señala expresamente "que las mencionadas modificaciones estriban respecto de los modelos tipos de actas constitutivas, haciéndolo extensivo a todas las actividades económicas" [cursivas añadidas].

Entre las principales actividades que estas cooperativas llevaron a cabo -muchas de ellas siguieron haciéndolo pese al cambio de línea política en el Gobierno nacional con la asunción, a fines del 2015, del Ing. Mauricio Macri, el cual cambió el eje de la política social por lo que algunos han denominado la "descooperativización" de los programas sociales-, se encontraban las de construcción, textil, desmalezamiento y saneamiento, así como mantenimiento de espacios públicos, entre otras. Lógicamente, una de las actividades más realizadas fue la de barrido y limpieza de espacios públicos en diversos municipios y localidades del todo el país.

Podemos afirmar que esta política obvió en forma total lo previsto en el Decreto N. ${ }^{\circ} 2015 / 94$ y en su reglamentación, al habilitarse nuevas cooperativas que brindaban servicios que aquellas prohíben, como, por ejemplo, los de limpieza.

Así, entonces, ¿cuántas miles de excepciones resiste una normativa que se supone es regla? El Inaes otorgó a estas cooperativas números de matrícula de la misma forma en que lo hacía con aquellas otras entidades que se conformaron a lo largo de esos años por fuera de esas políticas sociales impulsadas por el Estado.

No obstante, es cierto que se dieron situaciones cercanas a la esquizofrenia, ya que las mismas áreas del Inaes que aprobaban en tiempo récord cientos de nuevas cooperativas de trabajo - unas 3026- que realizarían tareas de limpieza en sus comunidades, a la vez rechazaban otorgar otras matrículas en razón a lo previsto en el "2015". 


\section{Las Leyes N. ${ }^{\circ} 25.250$ y 25.877}

Durante el Gobierno del Dr. Fernando De la Rúa, el Congreso Nacional sancionó una ley muy cuestionada por los sectores sindicales en razón a su contenido flexibilizador, de manera que se efectuaron denuncias que señalaban cómo senadores de la Nación habían recibido dádivas a cambio de su voto positivo. Esto trajo aparejado una grave crisis política, la cual culminaría -en el marco de una profunda recesión económicaen la crisis de fines del 2001 y la renuncia de de la Rúa a su cargo.

En el marco de este artículo cabe señalar que la Ley 25.250 de "Reforma Laboral" (B. 0. 02/06/2000) contenía un artículo por entero dedicado a las cooperativas de trabajo, el cual trataba aspectos semejantes a los contenidos en el Decreto 2015/94. Efectivamente, el artículo 4 en su primer párrafo señalaba:

Sin perjuicio de las facultades propias de la autoridad de fiscalización pública en materia cooperativa, los servicios de inspección de trabajo están habilitados para ejercer el contralor de las cooperativas de trabajo a los efectos de verificar el cumplimiento de las normas laborales y de la seguridad social en relación con los trabajadores dependientes a su servicio así como a los socios de ella que se desempeñaren en fraude a la ley laboral. Estos últimos serán considerados trabajadores dependientes de la cooperativa a los efectos de la aplicación de la legislación laboral y de la seguridad social.

Como se advierte, la norma no solo abarca los casos en los que se constate la venta de fuerza de trabajo o mano de obra a terceros, sino que hace referencia a cualquier situación en la que se verifique la existencia de fraude a la legislación laboral en las cooperativas de trabajo, incluso en el caso en que estas tengan personal en relación de dependencia debidamente declarados - situación que debería ser excepcional conforme lo autorizado por la Resolución INAC 360/75, aún vigente-.

Luego, se preveía que:

Si en el ejercicio de sus funciones esos servicios comprobaren que se ha incurrido en una desnaturalización de la figura cooperativa con el propósito de sustraerse total o parcialmente a la aplicación del ordenamiento laboral, deberán, sin perjuicio del ejercicio de su facultad de constatar las infracciones a las normas laborales en que de tal modo se hubiere incurrido y de proceder a su juzgamiento y sanción, denunciar 
esa circunstancia a la autoridad específica de fiscalización pública a los efectos del artículo 101 y concordantes de la ley 20.337.

Si recordamos el contenido del Decreto 2015/94, similares previsiones se hacían en caso de que los servicios de inspección del trabajo constataren incumplimientos a las normas laborales y de la seguridad social.

Ahora bien, el tercer y último párrafo del artículo $4^{\circ}$ contenía una prohibición concreta para las cooperativas de trabajo: "Las cooperativas de trabajo no podrán actuar como empresas de provisión de servicios eventuales, ni de temporada, ni de cualquier otro modo brindar servicios propios de las agencias de colocación".

Es decir, en el 2000, el legislador consideró necesario establecer pautas concretas para las cooperativas de trabajo en una ley de naturaleza laboral. Entre estas, estableció actividades que les quedaban expresamente vedadas, dos de las cuales ya estaban mencionadas en los considerandos del Decreto 2015/94 y el artículo $1^{\circ}$ de la Resolución INAC 1510/94 - servicios eventuales y agencia de colocación,- y otra no prevista allí - servicios de temporada-. En cambio, nada dijo respecto a las actividades de limpieza, seguridad y correos.

El artículo 34 de la Ley 25.250 derogaba de forma expresa varias normas -entre ellas decretos de la década de los noventa del siglo xx-, así como "toda otra norma que se oponga a la presente ley".

La Ley 25.250, sumamente cuestionada por las razones arriba referidas, mantuvo su vigencia hasta el mes de marzo del 2004, cuando fue derogada por la Ley N. ${ }^{\circ}$ 25.877 de Régimen Laboral (B. o. 19/03/2004). No obstante, la norma incorporó el "Capítulo III", destinado a las cooperativas de trabajo, el cual contiene un único artículo (40), el cual reproduce casi en su totalidad el texto del artículo 4 de la derogada Ley 25.250.

Por tanto, la prohibición expuesta en el último párrafo para las cooperativas de trabajo es aún la misma: “Las cooperativas de trabajo no podrán actuar como empresas de provisión de servicios eventuales, ni de temporada, ni de cualquier otro modo brindar servicios propios de las agencias de colocación".

\section{La Ley 26.727 de trabajo agrario}

A fines de diciembre del 2016 se sancionó y promulgó la Ley 26.727 (B. 0. 28/12/17) de Régimen de Trabajo Agrario. Esta, de acuerdo con la lógica de la Ley 25.877, y al ser una norma de carácter eminentemente laboral, destina un artículo a las cooperativas de trabajo con una redacción semejante. 
En efecto, el artículo 14 también hace referencia a controlar en las cooperativas de trabajo el cumplimiento de las normas laborales y de la seguridad social "en relación con los trabajadores dependientes a su servicio, así como a los socios de ella que se desempeñaren en fraude a la ley laboral".

Luego, señala que los trabajadores que se encuentren realizando tareas en fraude a la ley laboral o incumpliendo esta ley,

Serán considerados trabajadores dependientes de quienes contraten, subcontraten o cedieren total o parcialmente trabajos o servicios que integren el proceso productivo normal y propio del establecimiento a los efectos de la aplicación de la legislación laboral y de la seguridad social y serán responsables con sus contratistas, subcontratistas o cesionarios del cumplimiento de las normas relativas al trabajo y a la seguridad social.

En caso de constatarse "que se ha incurrido en una desnaturalización de la figura cooperativa con el propósito de sustraerse, total o parcialmente, a la aplicación de la legislación del trabajo", también se deberá denunciar esa circunstancia ante el Instituto Nacional de Asociativismo y Economía Social.

El párrafo final reitera prohibiciones establecidas en la Ley 25.877, en lo concerniente a servicios temporarios y agencias de colocación, sin referirse a los servicios eventuales: "Las cooperativas de trabajo no podrán actuar en el ámbito de la presente ley como empresas de provisión de trabajadores para servicios temporarios, ni de cualquier otro modo brindar servicios propios de las agencias de colocación".

Una cuestión particular es que en el artículo siguiente se hace extensiva la prohibición a todo tipo de empresa que prevea personal:

Se prohíbe la actuación de empresas de servicios temporarios, agencias de colocación o cualquier otra empresa que provea trabajadores para la realización de las tareas y actividades incluidas en la presente ley y de aquellas que de cualquier otro modo brinden servicios propios de las agencias de colocación (art. 15).

Complementa esto lo que se señala en el Decreto 301/2013 (B. 0. 22/03/2013), reglamentario de la Ley de Trabajo Agrario, el cual, al tratar lo previsto en el artículo 14, expresa: 
En el caso de socios aparentes de cooperativas que se desempeñaren en fraude a la ley laboral, éstas serán responsables junto con sus contratistas, subcontratistas o cesionarios del cumplimiento de las normas relativas al trabajo y a la seguridad social.

De esta manera amplía la obligación de la autoridad administrativa del trabajo de comunicar a la Administración Federal de Ingresos Públicos (AFIP), así como a la Administración Nacional de la Seguridad Social (Anses), "las irregularidades detectadas a los fines de la regularización de los trabajadores frente a la seguridad social".

\section{Conclusiones}

Este autor comparte la idea según la cual actividades como las desarrolladas por las agencias de colocación de personal o de servicios eventuales no son sencillas de conciliar con el formato cooperativo, debido a las grandes dificultades que se presentan en el funcionamiento democrático de las entidades y el escaso o nulo compromiso de los asociados. No obstante, la prohibición que contienen el Decreto 2015/94 y las leyes que luego se sancionaron se basa en un prejuicio que parte desde el mismo Estado, el cual, en definitiva, opta por los más "fácil": la prohibición.

Más aún cuando lo que se prohíbe no son modalidades de efectuar el trabajo, sino actividades en sí mismas, como, por ejemplo, las de seguridad, limpieza o correo. Esto constituye claramente una vulneración a principios constitucionales básicos y resulta contraria a la obligación de promoción y desarrollo que tiene el Estado para con el cooperativismo. Restringe así claras posibilidades de acceso al trabajo autogestionado de hombres y mujeres que deciden libremente ejercer dichas actividades mediante una noble figura como la de la cooperativa, la que no tiene correlato con otras figuras previstas en la legislación, de modo que no queda otra opción que conformar entidades basadas en la primacía del capital.

Debe quedar claro que la del Decreto 2015/94 no es la única prohibición que desde el Estado se le establece a las cooperativas, ${ }^{7}$ pero ciertamente es la que más repudio merece; de allí que en el título de este trabajo manifestamos la necesidad imperiosa que existe para que esa normativa sea derogada.

Ahora bien, sin que tengamos que recurrir a un fallo de la justicia que señale cómo estas normativas son claramente violatorias del derecho constitucional de asociarse con fines útiles y de trabajar, consideramos que la prohibición a las actividades

7 Por ejemplo, durante muchos años, a las cooperativas y mutuales les estuvo vedada la probabilidad de prestar servicios de radiodifusión. 
de correo, limpieza y seguridad, expresamente previstas en la Resolución 1510/94, no tienen sustento legal y debería modificarse.

¿Por qué inferimos esto? Puesto que, después de la expedición del Decreto 2015/94 -al que reglamenta la Resolución 1510/94-, en tres ocasiones el Congreso de la Nación legisló lo referido a las prohibiciones que tienen las cooperativas de trabajo, y en ninguna de ellas señaló actividades en sí mismas, sino modalidades de desarrollar la prestación de servicios, como, por ejemplo, las que llevan a cabo las empresas de servicios eventuales, de colocación de personal y de trabajo temporarios, las cuales tienen -cada una- una regulación distintiva.

Por tanto, en atención a que pautas básicas en la interpretación del derecho señalan que norma superior deroga norma inferior, y norma posterior deroga norma anterior -en nuestro caso, las Leyes 25.877 y 26.727 respecto al Decreto 2015/94-, cabe inferir que el Decreto 2015/94 ha perdido vigencia legal. Debería entonces seguir dicha suerte la Resolución INAC 1510/94.

Ahora bien, en el 2007 el Inaes la incorporó en el listado de resoluciones vigentes, ${ }^{8}$ pese a que por entonces ya estaba en vigencia el artículo 40 de la Ley 25.877. Consideramos en este caso que el Instituto debería revisar esta incorporación o, en si es necesario, modificar su texto, de forma tal que ya no sea una norma reglamentaria del Decreto 2015/94, sino un texto que haga lo propio con el artículo 40 de la Ley 25.877. Además, en dicha modificación debería eliminarse del listado de actividades "prohibidas" las de correo, limpieza y seguridad, ya que esto no está previsto en las leyes del Congreso actualmente vigentes (25.877 y 26.727). Todo esto en línea con la función asignada por el legislador al Inaes, en lo concerniente a "promover el perfeccionamiento de la legislación sobre cooperativas" (Ley 20.337, art. 106, inc. 6).

Lógicamente esto no implica abandonar el control del correcto funcionamiento de las cooperativas de trabajo por parte de la autoridad de aplicación de su régimen legal, que es, en definitiva, lo que el Estado hizo cuando en 1994 directamente vedó la posibilidad de reconocer personería a cooperativas de trabajo que incluyeran algunas de esas actividades, las cuales en sí mismas son totalmente lícitas.

De esta manera, se eliminarán restricciones legales que discriminan por completo a las cooperativas, y contrarias al rol del Estado (vía Inaes) de "concurrir a su promoción y desarrollo" (Ley 20.337, art. 105), sin perder, por parte de este último, el ejercicio de la fiscalización pública (Ley 20.337, art. 106, inc. $2^{\circ}$ ).

8 Véase la Resolución N. ${ }^{\circ}$ 1810/07, "Anexo i". 


\section{Referencias}

Constitución de la Nación Argentina: publicación del Bicentenario (2010). Buenos Aires: Corte Suprema de Justica de la Nación / Biblioteca del Congreso de la Nación / Biblioteca Nacional.

Cornaglia, R. J. (2003, octubre 22). La subcontratación de servicios por medio de cooperativas de trabajo. El control de constitucionalidad del decreto 2015/94, la ley 25.250 y el decreto 1002/99. Revista Doctrina Judicial, La Ley, XIX(43), 516.

Decreto 2015/94. Noviembre 14 de 1994. B. O. 16/11/1994.

Gleyzer, A. (1997a). Proyectos de ley de cooperativas de trabajo. Revista Idelcoop, (105). Recuperado de https://www.idelcoop.org.ar/revista/105/proyectos-ley-cooperativas-trabajo

Gleyzer, A. (1997b). Régimen legal de las Cooperativas de Trabajo. Revista Idelcoop, (109). Recuperado dehttps://www.idelcoop.org.ar/revista/109/regimen-legal-cooperativas-trabajo

Gordillo, A. (2013). Tratado de Derecho Administrativo y obras selectas, Tomo I, Capítulo VII. Buenos Aires: Fundación de Derecho Administrativo. Recuperados de https://www.gordillo.com/ tomo1.php

Ley de Cooperativas 20.337 (2012). Buenos Aires: Intercoop Editora Cooperativa Limitada.

Ley 25.250 de Reforma Laboral. Mayo 11 de 2000. B. 0. 02/06/2000.

Ley 25.877 de Régimen Laboral. Marzo 3 de 2004. B. o. 19/03/2004.

Ley 26.727 de Régimen de Trabajo Agrario. Diciembre 28 de 2017. B. 0. 28/12/17.

Resolución INAC 1510/94. Noviembre 16 de 1994. B. 0. 22/11/1994.

Resolución INAES 3026/06. Septiembre 26 de 2006. B. 0. 03/10/2006.

Schujman, M. (2015). Las cooperativas de trabajo en América Latina. Rosario: Ediciones del Revés. Recuperado de http://www.relats.org/foroess.html

Sosa, G. A. (2012). El fallo “Lago Castro" de la Corte Suprema y su recepción por parte de la Cámara de Trabajo. Revista Idelcoop, №212, pág. 201. Recuperado de https://www.idelcoop.org.ar/ revista/212/fallo-lago-castro-corte-suprema-y-su-recepcion-parte-camara-trabajo 
Sosa, G. A. (2018). Matrículas de cooperativas aprobadas por el Inaes en los años 2015, 2016 y 2017. Revista Idelcoop, №224, pág. 187. Recuperado de https://www.idelcoop.org.ar/revista/224/ matriculas-cooperativas-aprobadas-inaes-anos-2015-2016-y-2017

Vuotto, M. (2011). El cooperativismo de trabajo en la Argentina: contribuciones para el diálogo social. Lima: OIT/Programa Regional para la Promoción del Diálogo y la Cohesión Social en América Latina. 